\title{
One-Carbon Vitamins, Epigenetic/Genetic Integrity and Colon Cancer: Research is Needed to Understand the Effect on Tumorigenic Signaling Pathways
}

\section{Zhenhua Liu*}

Jean Mayer USDA Human Nutrition Research Center on Aging and Friedman School of Nutrition Science and Policy, Tufts University, 711 Washington Street, Boston, MA, 02111, USA

Evidencehas established the protective effect of folic acid fortification and periconceptional supplementation on neural tube defects. A large and growing body of compelling evidence from both epidemiological and pre-clinical studies also indicates that adequate folate status, and possibly in combination with other one-carbon nutrients, is associated with a decreased risk of colorectal carcinogenesis [1,2]. Evidence is still accumulating in support of these claims, but some recent studies raise warnings in regard to the safety for use folate as a chemopreventive component. Not to mention some null observations [3,4], it is important to point out that some studies suggest that overly abundant intake of folate may paradoxically promote tumor progression if administered in an inopportune time when an individual already has harbored foci of precancerous or cancerous cells [5-8]. To fully take advantage of this chemopreventive agent and avoid its cancer-promoting effect (though more studies are needed to confirm), research is urgently needed to understand specific molecular mechanisms by which these paradoxical effects are mediated.

A major biochemical function of folate is to serve as an essential conveyor of one-carbon units necessary for biological methylation and nucleotide syntheses via one-carbon metabolism [9]. Three other B-vitamins (B2, B6 and B12) are also involved in this metabolic network and therefore together with folate were called "One-carbon Vitamins" here. Vitamin B12 is a co-factor for methionine synthase. Vitamin B6 is a necessary co-factor for the inter-conversion between different co-enzymatic forms of folate. Vitamin B2 is the precursor of the cofactor for methylenetetrahydrofolate reductase [10]. This one-carbon metabolism network is the universal source for most, if not all, biological reactions which request methyl group. On one hand, the methyl donor for DNA methylation is derived from $S$-adenosyl methionine, which in turn obtains the moiety from 5-methyltetrahydrofolate via methionine as the intermediate. Not surprisingly, inadequate delivery of onecarbon vitamins has been reported to produce low levels of methylation in various experimental settings $[10,11]$. On the other hand, folate, in the form of 5,10-methylenetetrahydrofolate, is required for the synthesis of thymidine from uracil. Therefore, limited availability of folate promotes the misincorporation of uracil into DNA, as has been reproducibly shown in cell culture, animal models, and humans [1214].

It is well established that folate, in conjunction with other onecarbon nutrients, lies at the intersection of metabolic pathways that are involved in DNA methylation and nucleotide synthesis, but it falls short to explain various and even paradoxical functions of folate observed in epidemiological and pre-clinical studies. To properly explore the benefits of this agent, research on specific cellular signaling pathways is needed to elucidate the dual cancer-protective and potential deleterious effect shown in recent publications [5,15]. Most colorectal carcinomas arise from adenomas, which, via multiple steps, gradually progress into carcinomas. Different cellular signaling pathways drive the progression along the gradually progressing cascade $[16,17]$. Clear understanding the effect of one-carbon vitamins on those pathways which controls the progression at different stages should significantly contribute the development of intelligent dietary strategies for the prevention of colorectal cancer, but surprisingly, research in this setting is just at the early stage with limited experimental support.

Aberrant Wnt-signaling is an early event in $90 \%$ of human colorectal cancers and is thought to play an important role in the development of colorectal cancer, particularly at the initiation stage [18]. In 2000, our lab reported that $A p c$ expression is impaired by a severe degree of folate depletion in the rat colon [19]. In 2007, I demonstrated that mild depletion of folate, when present in conjunction with the mild depletion of other B-vitamins (B2, B6 and B12), alters several components of Wnt pathway in the colonic mucosa in a pro-transformational manner [10]. More recently, using a Wnt-reporter mouse model and a colorectal cancer mouse model, I further demonstrated that the combined one-carbon vitamin depletion (folate in conjunction with B2, B6 and B12 depletion) does increase the Wnt-signaling accompanying with elevated tumor incidence [20]. Moreover, other investigators have also observed significant changes in the expression of several modulators of the Wnt pathway, such as WISP1, WNT5Aand DKK-1, as a result of folate depletion [21]. Indirect evidence that folate depletion alters the Wnt pathway can also be drawn from studies of the rodent model of folate-sensitive neural tube birth defects, the crooked tail mouse, the genetic basis of which is a mutation in Lrp6, a Wnt co-receptor [22]. These findings of ours and others collectively indicate dietary one-carbon vitamins modulate colorectal tumorigenesis, at least in part, via alterations in the Wnt pathway, providing evidence in support of the preventive effect of folate at the early stage, but further studies are requested to understand how one-carbon vitamins mediate this critical pathway, and therefore diet-based or pharmaceutical strategies targeting this pathway can be developed.

The most acceptable explanation of cancer-promoting effect once the proneoplastic lesion is developed lies on folate as a cofactor in nucleotide synthesis. Hyper-proliferation is a feature of most dysplastic neoplasms, which request abundant availability of vitamins to meet the rapidly dividing cells for DNA synthesis [23]. Evidence of this effect has been reported in both animal models $[8,24-26]$ as well as clinical trials $[5,15,27]$. However, it is entirely unknown how one-carbon vitamins accelerates the progression of colorectal cancer via altering those signaling pathways in a manner which facilitates the progression in later stages, such as KRAS, P53, and SMAD pathways. In contrast, the integrity (including region-specific methylation and strand breaks)

*Corresponding author: Zhenhua Liu, Ph.D, Jean Mayer USDA Human Nutrition Research Center on Aging and Friedman School of Nutrition Science and Policy, Tufts University, 711 Washington Street, Boston, MA, 02111, USA, Tel: 617-556-3234; Fax 617-556-3234; E-mail: zhenhua.liu@tufts.edu

Received April 12, 2012; Accepted April 12, 2012; Published April 16, 2012

Citation: Liu Z (2012) One-Carbon Vitamins, Epigenetic/Genetic Integrity and Colon Cancer: Research is Needed to Understand the Effect on Tumorigenic Signaling Pathways. Vitam Trace Elem 1:e112.

Copyright: () 2012 Liu Z. This is an open-access article distributed under the terms of the Creative Commons Attribution License, which permits unrestricted use, distribution, and reproduction in any medium, provided the original author and source are credited. 
of P53, which inhibits the transformation from large adenoma to cancer at the later stage, is better protected with folate sufficiency in both cell culture [28,29] and animal models [30-32] when compared to folate deficiency. These observations show that a protective effect of folate, rather than a deleterious effect, at the later stage during the progression from large adenomas to carcinomas. These observations at the molecular level are inconsistent with the cancer-promoting effect suggested in the recent clinical trials $[5,15,27]$.

In addition to the abovementioned mechanisms, several other cellular pathways have been investigated, though in a lesser degree comparing the Wnt pathway, as the means by which folate inadequacy mediates carcinogenesis. For incidence, age-related enhancement of p16 promoter methylation occurred in a manner dependent dietary folate status, but surprisingly, this promoter hypermethylation in old animals with folate repletion and supplementation is associated with an increase of p16 expression [33], which is opposite to a general understanding that promoter hypermethylation is associated with a suppression of gene expression. Genome-wide expression microarrays have been utilized to screen for cellular pathways by which folate mediates colorectal carcinogenesis [34,35]. The expression of a quite amount of genes, falling into several functional categories, was substantially and significantly altered by folate depletion. Although a discussion of all of them is beyond the scope of this article, it is of interest that the transcriptional alteration of $a p c$ and $\beta$-catenin, the critical elements in Wnt pathway, as well as p53 gene were observed under the status of folate depletion, in concordance with the observations in our animal studies described above.

In summary, it is clear that the relationship between folate and the development of colorectal cancer is complex, and the underlying mechanism(s) is particularly insufficient for understanding the paradoxical effects and for developing dietary strategies. Epidemiologic studies should expand their investigations toward molecular level. Of more urgency are mechanistic studies, which were surprisingly much lesser than observational studies, to understand the biological relevance.

\section{Acknowledgements}

Support in part by grants from The Prevent Cancer Foundation and the U.S Department of Agriculture, under Contract Agreement (No. 1950-074-01S). Any opinions, findings, conclusions or recommendations expressed in this publication are those of the author(s) and do not necessarily reflect the view of the U.S. Department of Agriculture.

\section{References}

1. Giovannucci E (2002) Epidemiologic studies of folate and colorectal neoplasia: a review. J Nutr 132: $2350 \mathrm{~S}-2355 \mathrm{~S}$

2. Kim YI (2004) Folate, colorectal carcinogenesis, and DNA methylation: lessons from animal studies. Environ Mol Mutagen 44: 10-25.

3. Eussen SJ, Vollset SE, Igland J, Meyer K, Fredriksen A, et al. (2010) Plasma folate, related genetic variants, and colorectal cancer risk in EPIC. Cancer Epidemiol Biomarkers Prev 19: 1328-1340.

4. Wolpin BM, Wei EK, Ng K, Meyerhardt JA, Chan JA, et al. (2008) Prediagnostic plasma folate and the risk of death in patients with colorectal cancer. $\mathrm{J}$ Clin Oncol 26: 3222-3228.

5. Cole BF, Baron JA, Sandler RS, Haile RW, Ahnen DJ, et al. (2007) Folic acid for the prevention of colorectal adenomas: a randomized clinical trial. JAMA 297: 2351-2359

6. Mason JB, Dickstein A, Jacques PF, Haggarty P, Selhub J, et al. (2007) A temporal association between folic acid fortification and an increase in colorectal cancer rates may be illuminating important biological principles: a hypothesis. Cancer Epidemiol Biomarkers Prev 16: 1325-1329.

7. Song J, Medline A, Mason JB, Gallinger S, Kim YI (2000) Effects of dietary folate on intestinal tumorigenesis in the apcMin mouse. Cancer Res 60: 54345440.

8. Song J, Sohn KJ, Medline A, Ash C, Gallinger S, Kim YI (2000) Chemopreventive effects of dietary folate on intestinal polyps in Apc+/- Msh2-/- mice. Cancer Res 60: 3191-3199

9. Lamprecht SA, Lipkin M (2003) Chemoprevention of colon cancer by calcium vitamin D and folate: molecular mechanisms. Nat Rev Cancer 3: 601-14.

10. Liu Z, Choi SW, Crott JW, Keyes MK, Jang H, et al. (2007) Mild depletion of dietary folate combined with other $\mathrm{B}$ vitamins alters multiple components of the Wnt pathway in mouse colon. J Nutr 137: 2701-2708.

11. Pufulete M, Emery PW, Sanders TA (2003) Folate, DNA methylation and colorectal cancer. Proc Nutr Soc 62: 437-445.

12. Duthie SJ, Hawdon A (1998) DNA instability (strand breakage, uracil misincorporation, and defective repair) is increased by folic acid depletion in human lymphocytes in vitro. FASEB J 12: 1491-1497.

13. Blount BC, Mack MM, Wehr CM, MacGregor JT, Wang G, et al. (1997) Folate deficiency causes uracil misincorporation into human DNA and chromosome breakage: implications for cancer and neuronal damage. Proc Natl Acad Sci U S A 94: 3290-3295.

14. Choi SW, Friso S, Dolnikowski GG, Bagley PJ, Edmondson AN, et al. (2003) Biochemical and molecular aberrations in the rat colon due to folate depletion are age-specific. J Nutr 133: 1206-1212.

15. Ebbing M, Bonaa KH, Nygard O, Arnesen E, Ueland PM, et al. (2009) Cance incidence and mortality after treatment with folic acid and vitamin B12. JAMA 302: $2119-2126$

16. Fearon ER, Vogelstein B (1990) A genetic model for colorectal tumorigenesis Cell 61: 759-767

17. Markowitz SD, Bertagnolli MM (2009) Molecular origins of cancer: Molecula basis of colorectal cancer. N Engl J Med 361: 2449-2460

18. Suzuki H, Watkins DN, Jair KW, Schuebel KE, Chen WD, et al. (2004) Epigenetic inactivation of SFRP genes allows constitutive WNT signaling in colorectal cancer. Nat Genet 36: 417-422.

19. Kim YI, Shirwadkar S, Choi SW, Puchyr M, Wang Y, et al. (2000) Effects of dietary folate on DNA strand breaks within mutation-prone exons of the p53 gene in rat colon. Gastroenterology 119: 151-161.

20. Liu Z, Ciappio ED, Crott JW, Brooks RS, Nesvet J, et al. (2011) Combined inadequacies of multiple $B$ vitamins amplify colonic Wnt signaling and promote intestinal tumorigenesis in BAT-LacZxApc1638N mice. FASEB J 25: 31363145.

21. Katula KS, Heinloth AN, Paules RS (2007) Folate deficiency in normal human fibroblasts leads to altered expression of genes primarily linked to cell signaling, the cytoskeleton and extracellular matrix. J Nutr Biochem 18: 541-552.

22. Carter M, Chen X, Slowinska B, Minnerath S, Glickstein S, et al. (2005) Crooked tail (Cd) model of human folate-responsive neural tube defects is mutated in Wnt coreceptor lipoprotein receptor-related protein 6. Proc Natl Acad Sci U S A 102: 12843-12848

23. Voeller D, Rahman L, Zajac-Kaye M (2004) Elevated levels of thymidylate synthase linked to neoplastic transformation of mammalian cells. Cell Cycle 3: 1005-1007

24. Le Leu RK, Young GP, McIntosh GH (2000) Folate deficiency diminishes the occurrence of aberrant crypt foci in the rat colon but does not alter global DNA methylation status. J Gastroenterol Hepatol 15: 1158-1164.

25. Kim YI, Salomon RN, Graeme-Cook F, Choi SW, Smith DE, et al. (1996) Dietary folate protects against the development of macroscopic colonic neoplasia in a dose responsive manner in rats. Gut 39: 732-740.

26. Kotsopoulos J, Sohn KJ, Martin R, Choi M, Renlund R, et al. (2003) Dietary folate deficiency suppresses $\mathrm{N}$-methyl-N-nitrosourea-induced mammary tumorigenesis in rats. Carcinogenesis 24: 937-944.

27. Van Guelpen B, Hultdin J, Johansson I, Hallmans G, Stenling R, et al. (2006) Low folate levels may protect against colorectal cancer. Gut 55: 1461-1466.

28. Wasson GR, McGlynn AP, McNulty H, Strain JJ, Scott J, et al. (2006) Globa DNA and p53 region-specific hypomethylation in human colonic cells is induced by folate depletion and reversed by folate supplementation. J Nutr 136: 2748 2753. 
Citation: Liu Z (2012) One-Carbon Vitamins, Epigenetic/Genetic Integrity and Colon Cancer: Research is Needed to Understand the Effect on Tumorigenic Signaling Pathways. Vitam Trace Elem 1:e112.

29. Crott JW, Liu Z, Choi SW, Mason JB (2007) Folate depletion in human lymphocytes up-regulates p53 expression despite marked induction of strand breaks in exons 5-8 of the gene. Mutat Res 626: 171-179.

30. Liu Z, Choi SW, Crott JW, Smith DE, Mason JB (2008) Multiple B-vitamin inadequacy amplifies alterations induced by folate depletion in p53 expression and its downstream effector MDM2. Int J Cancer 123: 519-525.

31. Sohn KJ, Stempak JM, Reid S, Shirwadkar S, Mason JB, et al. (2003) The effect of dietary folate on genomic and p53-specific DNA methylation in rat colon. Carcinogenesis 24: 81-90.

32. Kim YI, Pogribny IP, Basnakian AG, Miller JW, James SJ, et al. (1997) Folate deficiency in rats induces DNA strand breaks and hypomethylation within the p53 tumor suppressor gene. Am J Clin Nutr 65: 46-52.
33. Keyes MK, Jang H, Mason JB, Liu Z, Crott JW, et al. (2007) Older age and dietary folate are determinants of genomic and p16-specific DNA methylation in mouse colon. J Nutr 137: 1713-1717.

34. Crott JW, Choi SW, Ordovas JM, Ditelberg JS, Mason JB (2004) Effects of dietary folate and aging on gene expression in the colonic mucosa of rats: implications for carcinogenesis. Carcinogenesis 25: 69-76.

35. Novakovic P, Stempak JM, Sohn KJ, Kim YI (2006) Effects of folate deficiency on gene expression in the apoptosis and cancer pathways in colon cancer cells. Carcinogenesis 27: 916-924. 